\title{
Synthesis and Adsorption Properties of $\mathrm{Ti}_{2} \mathrm{O}\left(\mathrm{PO}_{4}\right)_{2} \cdot 2 \mathrm{H}_{2} \mathrm{ONanobelts}$
}

$$
\text { Po } \mathrm{LI}^{\mathrm{a}} \text {, Xiao-Gang WEN }{ }^{\mathrm{b}^{\star}} \text { and Sheng-Xuan } \mathrm{LIN}^{\mathrm{c}} \text {, }
$$

School of Material Science and Engineering,SichuanUniversity, Chengdu, 610065, P. R. China

aaiwei2046@163.com

bwenxg@scu.edu.cn

clinshengxuan1688@126.com

Keywords: Nanobelts, Titanium phosphates, Adsorption, Methylene blue

\begin{abstract}
Ti}_{2} \mathrm{O}\left(\mathrm{PO}_{4}\right)_{2} \cdot 2 \mathrm{H}_{2} \mathrm{O}$ nanobelts were successfully synthesized by a simple, template and surfactant-free hydrothermal method,in which titanium sulfate( $\left.\mathrm{Ti}\left(\mathrm{SO}_{4}\right)_{2}\right)$ and concentrated phosphoric acid $\left(\mathrm{H}_{3} \mathrm{PO}_{4}\right)$ were used as titanium and phosphorus source, respectively. The synthesized materials were characterized by X-ray diffraction(XRD), Scanning electron microscopy (SEM), Fourier transform infrared spectroscopy (FT-IR). The nanobelts are ca. $60 \mathrm{~nm}$ in width as well as $20 \mathrm{~nm}$ in thickness, and its length can reach several micrometers. The adsorption performance of the synthesized nanobelts was investigated. The results indicate that the $\mathrm{Ti}_{2} \mathrm{O}\left(\mathrm{PO}_{4}\right)_{2} \cdot 2 \mathrm{H}_{2} \mathrm{O}$ nanobelts have good adsorption ability to methylene blue (MB). The removal rate of $\mathrm{MB}$ could reach to $50 \%$ within $10 \mathrm{~min}$, the equilibrium adsorption time is about $70 \mathrm{~min}$ as well as the equilibrium capacity is about $150 \mathrm{mg} / \mathrm{g}$ at room temperature. It indicate that the $\mathrm{Ti}_{2} \mathrm{O}\left(\mathrm{PO}_{4}\right)_{2} \cdot 2 \mathrm{H}_{2} \mathrm{O}$ could be a promising candidates for waste water treatment. The possible adsorption mechanism was also suggested.
\end{abstract}

\section{Introduction}

The tetravalent titanium phosphates (TiP) have been synthesized and investigated for many years due to its excellent thermal and chemical stability. There are two kinds of titanium phosphate based on their $\mathrm{P} / \mathrm{Ti}$ ratio, one is the layered titanium phosphate with a $\mathrm{P} / \mathrm{Ti}$ ratio of $2: 1$, such as $\mathrm{Ti}\left(\mathrm{HPO}_{4}\right)_{2} \cdot \mathrm{H}_{2} \mathrm{O}$ and $\mathrm{Ti}\left(\mathrm{HPO}_{4}\right)_{2} \cdot 2 \mathrm{H}_{2} \mathrm{O}[1-3]$ and so on.Recent years, a kind of new titanium phosphates with a $\mathrm{P} / \mathrm{Ti}$ ratio of $1: 1$, including $\mathrm{TiO}(\mathrm{OH})\left(\mathrm{H}_{2} \mathrm{PO}_{4}\right) \cdot 2 \mathrm{H}_{2} \mathrm{O}$ and $\mathrm{Ti}_{2} \mathrm{O}_{3}\left(\mathrm{H}_{2} \mathrm{PO}_{4}\right)_{2} \cdot 2 \mathrm{H}_{2} \mathrm{O}$ have been synthesized[4-7].The TiP compounds have various crystal structures based on their composition[8-11], and can play an important role in the application of ions exchange[12], ion adsorption[5,13], superhydrophilic or superhydrophobic surface[14], catalyst[15,16] and lithium ion battery[17]. However, to the best of our knowledge, the investigation on the adsorption properties of TiP has not been reported yet. On the other hand, aim to reduce the environmental pollution which is getting worse,it's urgent to developnew adsorbent materials with excellent adsorption performance and stability.In the present article, we have synthesized a novel $\mathrm{Ti}_{2} \mathrm{O}_{(}\left(\mathrm{PO}_{4}\right)_{2} \cdot 2 \mathrm{H}_{2} \mathrm{O}$ nanobelts, to our knowledge, the belt-like $\mathrm{Ti}_{2} \mathrm{O}\left(\mathrm{PO}_{4}\right)_{2} \cdot 2 \mathrm{H}_{2} \mathrm{O}$ nanostructures have not been reported yet. We also measured the adsorption properties of synthesized $\mathrm{Ti}_{2} \mathrm{O}\left(\mathrm{PO}_{4}\right)_{2} \cdot 2 \mathrm{H}_{2} \mathrm{O}$ nanobelts, and it demonstrates good adsorption ability to methylene blue.

\section{Experimental Section}

The reagents of concentrated phosphoric acid $\left(\mathrm{H}_{3} \mathrm{PO}_{4}, \geqslant 85.0 \%\right)$, hydrogen peroxide $\left(\mathrm{H}_{2} \mathrm{O}_{2}, \geqslant\right.$ $30.0 \%)$, ethanol $\left(\mathrm{C}_{2} \mathrm{H}_{5} \mathrm{OH}, \geqslant 99.7 \%\right)$, and distilled water were purchased from Chengdu Kelong Chemical Reagent Co.Ltd; titanium sulfate $\left(\mathrm{Ti}\left(\mathrm{SO}_{4}\right)_{2}, \geqslant 96.0 \%\right)$ was purchased from Sinopharm Chemical Reagent Co.Ltd, all the chemicals are of analytical grade and were used without further purification.

$\mathrm{Ti}_{2} \mathrm{O}\left(\mathrm{PO}_{4}\right)_{2} \cdot 2 \mathrm{H}_{2} \mathrm{O}$ nanobelts were synthesized as follow: At first, $20 \mathrm{ml}$ of distilled water was

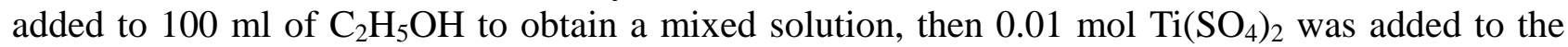
mixed solution under vigorous stirring. When $\mathrm{Ti}\left(\mathrm{SO}_{4}\right)_{2}$ was dissolved completely, $15 \mathrm{ml}$ of above 
solution was transferred to a $25 \mathrm{ml}$ Teflon-lined stainless autoclave and $0.5 \mathrm{ml}$ of concentrated phosphoric acid and hydrogen peroxide was added into the solution under vigorous stirringfor a few minutes, then the autoclave was sealed and maintained at $180^{\circ} \mathrm{C}$ for $24 \mathrm{~h}$ in a electric oven. After cooling at room temperature, the precipitates were collected by centrifugation and washed with distilled water and ethanol until the $\mathrm{pH}$ value of supernatant was 7 . Finally, the product was dried in an vacuum drying oven at $80^{\circ} \mathrm{C}$ for $24 \mathrm{~h}$, the white powder is collected for further characterization and measurement.

The crystal structure of the samples were identified by X'Pert Pro MPD X-ray diffractometer (XRD, PANalytical B.V. Holland) using $\mathrm{Cu} K \alpha$ radiation $(\lambda=0.15406 \mathrm{~nm}, 40 \mathrm{kV}, 30 \mathrm{~mA})$ in the $2 \theta$ range $5-80^{\circ}$. The morphology of products were observed by using S-4800 Field emission scanning electron microscope(FESEM, Hitachi Co, Japan), Fourier transform infrared spectrum was investigated by using Nicolet 6700 Fourier Transform IR/Visible spectrometer(FT-IR, Thermo Nicolet Co. American) in a wavenumber range from 4000 to $400 \mathrm{~cm}^{-1}$.

Absorbance spectra of the samples were measured by using UV-1101 spectrophotometer (Techcomp, China). The adsorption performance of sample was estimated by measuring the adsorption of $\mathrm{MB}$ at ambient temperature and pressure. In a typical process, $20 \mathrm{mg}$ as-prepared product was added into $200 \mathrm{~mL}$ methylene blue (MB) solution with the concentration of $20 \mathrm{mg} / \mathrm{L}$ under vigorous stirring. After continuous stirring at $150 \mathrm{rpm}$ at a defined time interval, $5 \mathrm{~mL}$ of solution was taken out and centrifuged for $5 \mathrm{~min}$ at $8000 \mathrm{rpm}$. The supernatant was collected and measured using UV-Vis spectrophotometer. The adsorption performance was evaluated by calculating the removal rate of MB according to the absorbance.

\section{Results and Discussion}

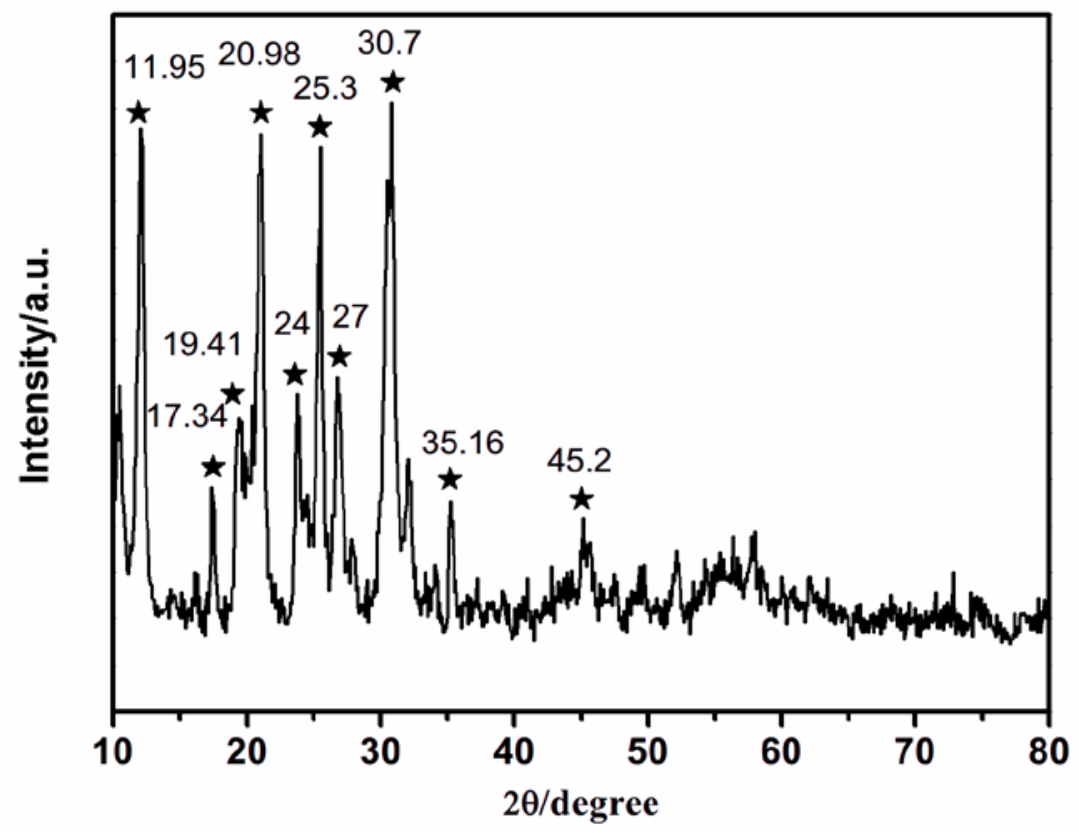

Fig. 1 The XRD pattern of as synthesized sample.

The XRD pattern of as-synthesized sample is shown in Figure 1. All the diffraction peaks could be indexed to $\mathrm{Ti}_{2} \mathrm{O}\left(\mathrm{PO}_{4}\right)_{2} \cdot 2 \mathrm{H}_{2} \mathrm{O}$ (JCPDS No. 52-1530). This compound has a skeleton-like structure. The strong reflection peak located at $2 \theta=11.95^{\circ}$ corresponds to the (110) crystal plane of $\mathrm{Ti}_{2} \mathrm{O}\left(\mathrm{PO}_{4}\right)_{2} \cdot 2 \mathrm{H}_{2} \mathrm{O}$ which with an interplanar spacing of $\left.7.39 \AA \AA^{[} 6,7,11\right]$. The product is pure and there is no other crystal phase is observed in the XRD pattern. 


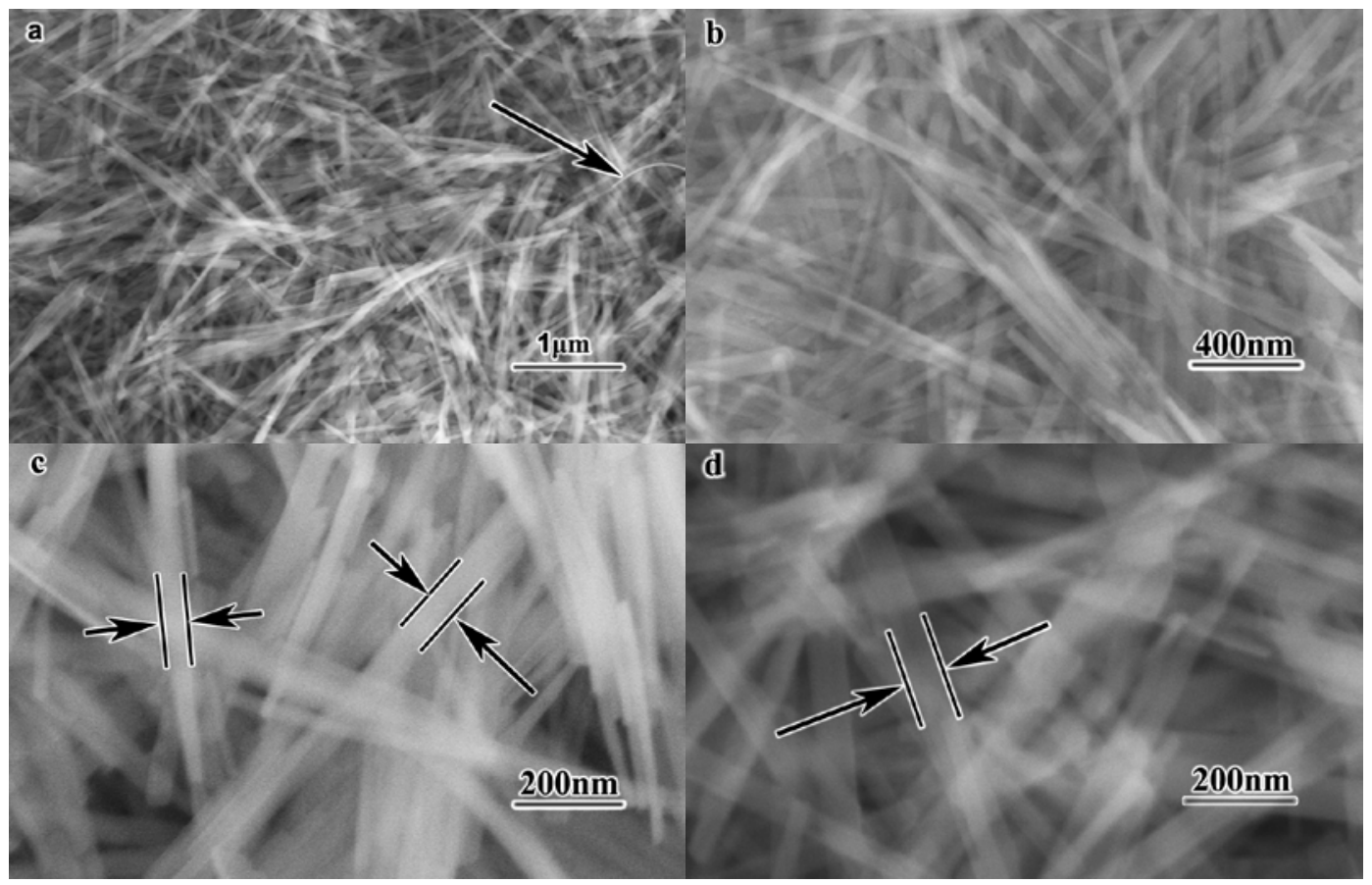

Fig. 2 SEM images of sample.

Figure 2 shows the SEM imagesof prepared $\mathrm{Ti}_{2} \mathrm{O}\left(\mathrm{PO}_{4}\right)_{2} \cdot 2 \mathrm{H}_{2} \mathrm{O}$ sample with different magnifications. The product are all $\mathrm{Ti}_{2} \mathrm{O}\left(\mathrm{PO}_{4}\right)_{2} \cdot 2 \mathrm{H}_{2} \mathrm{O}$ nanobelts. The belt-like morphology can be appreciated from the thinning in the smooth bent and wring section indicated by the black arrow in Figure 2a. There is no other nanostructures were observed. Figure $2 b$ to $2 \mathrm{~d}$ show the SEM images with higher magnification, it indicate that the nanobelts are 60nm in width and $20 \mathrm{~nm}$ in thickness, and its length can reach several micrometers. The nanobelts have a uniform width and thickness along the whole length, and the surface of nanobelts is very smooth.

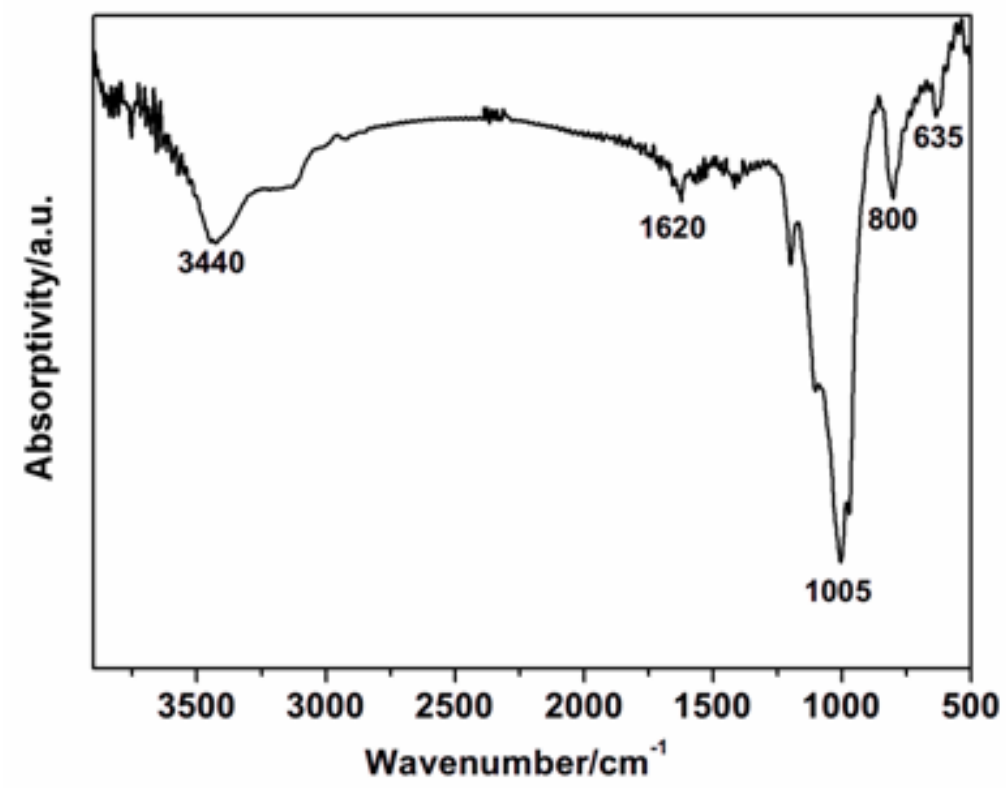

Fig. 3FT-IR spectrum of $\mathrm{Ti}_{2} \mathrm{O}\left(\mathrm{PO}_{4}\right)_{2} \cdot 2 \mathrm{H}_{2} \mathrm{O}$ nanobelts.

The infrared spectrum of $\mathrm{Ti}_{2} \mathrm{O}\left(\mathrm{PO}_{4}\right)_{2} \cdot 2 \mathrm{H}_{2} \mathrm{O}$ nanobelts is shown in Figure 3. The two peaks at 3440 and $1620 \mathrm{~cm}^{-1}$ can be assigned to the hydroxyl symmetrical stretching vibration mode of water molecule in the structure. Compare with literature, the intense absorbance band around $1005 \mathrm{~cm}^{-1}$ should be attributed to the characteristic bending Vibration of $\mathrm{P}-\mathrm{O}$ bond in $\mathrm{PO}_{4}$ groups. The peaks at $800 \mathrm{~cm}^{-1}$ can be assigned to the vibration mode of Ti-O bond of Ti-OH and Ti-O-Ti matrix in the 
$\mathrm{Ti}_{2} \mathrm{O}\left(\mathrm{PO}_{4}\right)_{2} \cdot 2 \mathrm{H}_{2} \mathrm{O}$ structure[6,7,11]. In addition, the weak peak located at $635 \mathrm{~cm}^{-1}$ should be attributed to mixed vibration mode of Ti-O bond and $\mathrm{PO}_{4}$ groups[6].

The absorption curves of MB after different adsorption time are shown in Figure 4 (a). It is obvious that the absorption peak intensity at $665 \mathrm{~nm}$ reduce rapidly in $10 \mathrm{~min}$, it indicate that the adsorption of nanobelts to $\mathrm{MB}$ is very fast at this stage, and then the adsorption rate decrease continuously companying increased adsorption time. About $75.69 \% \mathrm{MB}$ was removed after $70 \mathrm{~min}$. Figure 4(b) shows the corresponding adsorption rate curve. It shows the reductionof adsorption rate companying the increase adsorption time. The adsorption rate decreased significantly after 10 min. The $\mathrm{Ti}_{2} \mathrm{O}\left(\mathrm{PO}_{4}\right)_{2} \cdot 2 \mathrm{H}_{2} \mathrm{O}$ nanobeltssaturate with $\mathrm{MB}$ basically after $70 \mathrm{~min}$, the saturated adsorption capacity is ca. $150 \mathrm{mg} / \mathrm{g}$.

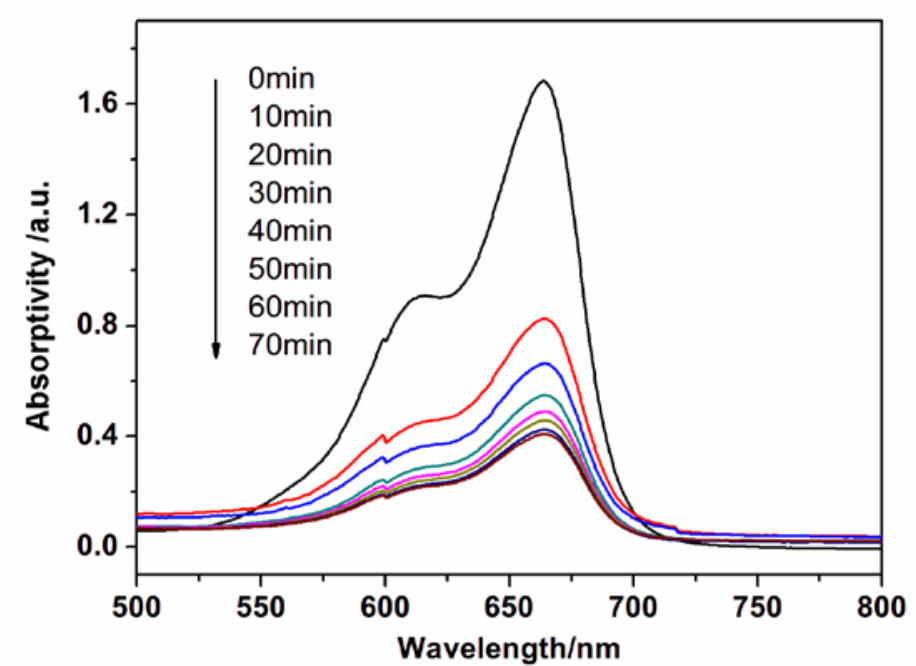

(a)

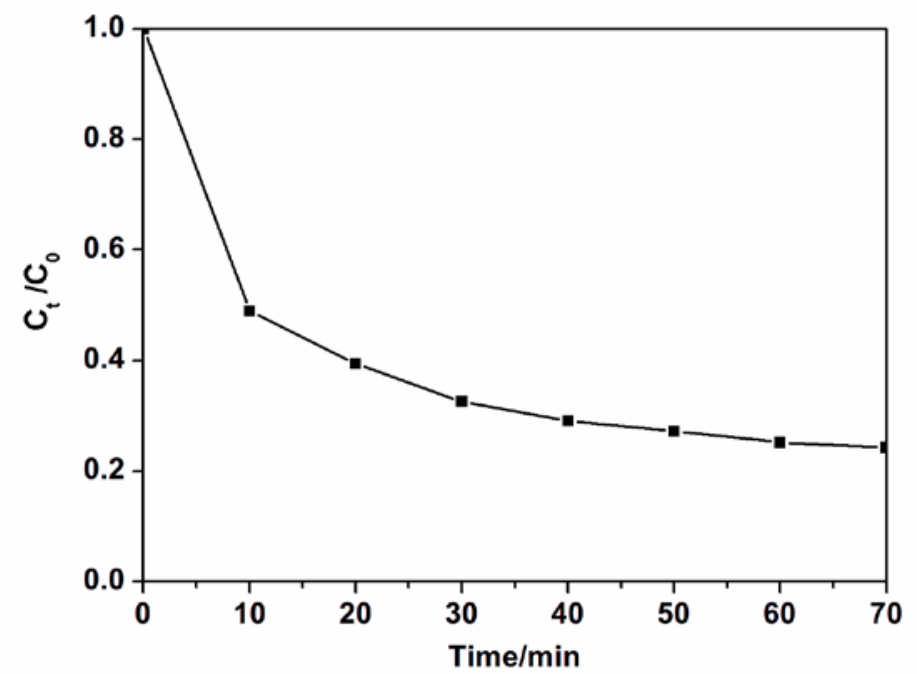

(b)

Fig. 4(a) Absorption spectra of $\mathrm{MB}$ after treatment with $\mathrm{Ti}_{2} \mathrm{O}\left(\mathrm{PO}_{4}\right)_{2} \cdot 2 \mathrm{H}_{2} \mathrm{O}$ nanobelts for different time intervals; (b) Corresponding adsorption rates of $\mathrm{Ti}_{2} \mathrm{O}\left(\mathrm{PO}_{4}\right)_{2} \cdot 2 \mathrm{H}_{2} \mathrm{O}$ nanobelts.

The good adsorption performance of $\mathrm{Ti}_{2} \mathrm{O}\left(\mathrm{PO}_{4}\right)_{2} \cdot 2 \mathrm{H}_{2} \mathrm{O}$ can be attributed to its inherent crystal structure and the high surface area of nanobelts. According to the previous study of Pooiary et al.[11], $\mathrm{Ti}_{2} \mathrm{O}\left(\mathrm{PO}_{4}\right)_{2} \cdot 2 \mathrm{H}_{2}$ Ohas a skeleton structure, it contains an oxygen bridged dimeric $\mathrm{TiO}_{6}$ octahedra and two independent phosphate groups $\left(\mathrm{PO}_{4}\right.$ tetrahedra) which is the basic structural unit of $\mathrm{Ti}_{2} \mathrm{O}\left(\mathrm{PO}_{4}\right)_{2} \cdot 2 \mathrm{H}_{2} \mathrm{O}$. There are two kinds of one-dimensional channels with different sizes parallel to the c-axis direction of the crystal structure due to the connected alternately of the $\mathrm{PO}_{4}$ tetrahedra and $\mathrm{TiO}_{6}$ octahedra ${ }^{[6,11]}$, and these channels with the space around it are likely to be area where the dye molecules can be adsorbed and stocked. In addition, according to the investigation of Bortun et 
al. ${ }^{[6]}$, the exchange between $\mathrm{Ti}_{2} \mathrm{O}\left(\mathrm{PO}_{4}\right)_{2} \cdot 2 \mathrm{H}_{2} \mathrm{O}$ and $\mathrm{Ti}_{2}(\mathrm{OH})_{2}\left(\mathrm{PO}_{4}\right)_{2} \cdot \mathrm{H}_{2} \mathrm{O}$ is suggested in a neutral and alkaline solution based on the possible existence of $\mathrm{Ti}-\mathrm{OH}$ functional groups, due to existence of this exchange process, one of the Ti-O bond in the Ti-O-Ti bridge will break, the channels in the $\mathrm{Ti}_{2} \mathrm{O}\left(\mathrm{PO}_{4}\right)_{2} \cdot 2 \mathrm{H}_{2}$ Oare opened and expanded which will facilitate the enter of more dye molecules or charged groups as well as the adsorption process can be promoted. On the other hand, more hydroxyl groups may generate from the equilibrium process mentionedabove, when the protons in $\mathrm{Ti}-\mathrm{OH}$ was released in solution, the molecules of products can be given a negative charge,meanwhile, the MB molecules can bring a positive charge when it was dissolved in water thus it can be adsorbed by the adsorbent through electrostatic attraction. The adsorption ability of adsorbent is related to its surface area, amount of active spot for adsorption and the space to hold the dye molecular, so the $\mathrm{Ti}_{2} \mathrm{O}\left(\mathrm{PO}_{4}\right)_{2} \cdot 2 \mathrm{H}_{2} \mathrm{O}$ nanobelts with high area exhibit good adsorption performance to $\mathrm{MB}$. Further research is needed in the future to understand thedetailed adsorption mechanismof $\mathrm{Ti}_{2} \mathrm{O}\left(\mathrm{PO}_{4}\right)_{2} \cdot 2 \mathrm{H}_{2} \mathrm{O}$.

\section{Conclusions}

Thepure and uniform $\mathrm{Ti}_{2} \mathrm{O}\left(\mathrm{PO}_{4}\right)_{2} \cdot 2 \mathrm{H}_{2} \mathrm{O}$ nanobelts were synthesized via a hydrothermal method at $180^{\circ} \mathrm{C}$, the titanium sulfate $\left(\mathrm{Ti}\left(\mathrm{SO}_{4}\right)_{2}\right)$ and concentrated phosphoric acid $\left(\mathrm{H}_{3} \mathrm{PO}_{4}\right)$ were used as precursors. The crystalline nanobelts demonstrate good adsorption ability to methylene blue at ambient temperature and pressure, the equilibrium adsorption time to $\mathrm{MB}$ is about $70 \mathrm{~min}$ and the saturated adsorption capacity and removal rate is about $150 \mathrm{mg} / \mathrm{g}, 76 \%$, respectively. The adsorption of nanobelts to MB was very fast, $50 \% \mathrm{MB}$ can be removed in $10 \mathrm{~min}$. The inherent and unique crystal structureand high special surface area of $\mathrm{Ti}_{2} \mathrm{O}\left(\mathrm{PO}_{4}\right)_{2} \cdot 2 \mathrm{H}_{2} \mathrm{O}$ induce its good adsorption performance, and the adsorption process is controlled by the ectrostatic attraction between adsorbent and dye molecules. Via surface modificationit is possible to further improve the performance of this new TiP nanomaterials in the future.

\section{Acknowledgments}

This work was supported by the National Natural Science Foundation of China (Grant No. 51072124) and Program for New Century Excellent Talents in University (No. NCET100605). We wish to thank the Analytical \& Testing Center of Sichuan University (SCU) for the assistance in sample characterization.

\section{References}

[1] S. Bruque, M. A.G. Aranda, E. R. Losilla, P. O. Pastor, P. M. Torres, Inorg. Chem.34(1995)893-899.

[2] A.M. Krogh Andersen, P. Norby,Inorg. Chem.37 (1998) 4313-4320.

[3] H. Hosono, Y. Abe,J. Non. Cryst. Solids. 139 (1992) 86-89.

[4] L. Kőrösi,S. Papp, I. Dékány. Chem. Mater. 22 (2010) 4356-4363.

[5] H. Takahashi, T. Oi. M. Hosoe, M. Hosoe, J. Mater. Chem. 12 (2002) 2513-2518.

[6] A. I. Bortun, S. A. Khainakov,L. N. Bortun,D. M. Poojary, J. Rodriguez, J. R. Garcia,A. Clearfield,Chem. Mater.9 (1997) 1805-1811.

[7] Y. Bereznitski, M. Jaroniec, A.I. Bortun, D. M. Poojary,A. Clearfield,J. Colloid. Interface. Sci. 191 (1997) 442-448.

[8] J. Soria, J. E. Iglesias, J. Sanz, J. Chem. Soc. Faraday Trans. 89 (1993) 2515-2518..

[9] A. N. Christensen, E. K. Andersen, I. G. K. Andersen, G. Alberti, M. Nielsen,M. S. Lehmann, Acta Chem. Scand.44 (1990) 865-872. 
[10]C. Serre, T. Corbière, C. Lorentz, F. Taulelle,G. Férey, Chem. Mater.15 (2003) 2328-2337.

[11]D. M. Poojary,A. I. Bortun, L. N. Bortun, A. Clearfield, J. Solid State Chem. 132 (1997) 213-223.

[12]A. Nilchi, M. G. Maragheh, A. Khanchi, M. A. Farajzadeh, A. A. Aghaei, J.Radioanal.Nucl.Chem. 261 (2004) 393-400.

[13]Xue-Yun WANG,Xiu-Lin YANG, Jian-Hua CAI,Ting-Ting MIAO,Li-Hua LI, Gen LI, Ding-Rong DENG, Li JIANG, Chun-Ru WANG, J. Mater. Chem. A 2 (2014) 6718-6722.

[14]M. Yada, Y. Inoue, A. Sakamoto, T. Torikai, T. Watari,ACS Appl. Mater. Interfaces.6 (2014): 7695-7704.

[15]A. Clearfield, D. S. Thakur,Appl. Catal.26 (1986) 1-26.

[16]M. P. Kapoor, I. Shinji, Y. Hisao,J. Phys. Chem. B 109 (2005) 9231-9238.

[17]M. S. Kishorea, V. Pralonga, V. Caignaerta, U.V. Varadarajub, B. Raveaua, J. Power Sources. 169 (2007) 355-360. 